\title{
High-intensity interval training improved fasting blood glucose and lipid profiles in type 2 diabetic rats more than endurance training; possible involvement of irisin and betatrophin
}

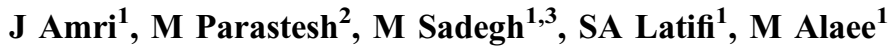 \\ ${ }^{1}$ Traditional and Complementary Medicine Research Center, Arak University of Medical Sciences, Arak, Iran \\ ${ }^{2}$ Department of Sports Physiology and Pathology, Faculty of Sport Sciences, Arak University, Arak, Iran \\ ${ }^{3}$ Department of Physiology, Faculty of Medicine, Arak University of Medical Sciences, Arak, Iran
}

Received: December 14, 2018

Accepted: July 26, 2019

\begin{abstract}
Background and aims: In this study, we aimed to investigate the effects of 10 weeks of high-intensity interval training (HIIT) and endurance training (END) on irisin, betatrophin, insulin, fasting blood glucose (FBG) concentrations, and lipid profiles in diabetic rats. Methods: Twenty-four Wistar rats (weight: 200-250 g) were randomly assigned into four groups as follows: (1) control (Cnt), (2) diabetic (Dibt), (3) diabetic HIIT (Dibt-HIIT), and (4) diabetic END (Dibt-END). For inducing diabetes, after $12 \mathrm{~h}$ of food starvation, nicotinamide $(120 \mathrm{mg} / \mathrm{kg})$ and streptozotocin (STZ; $65 \mathrm{mg} / \mathrm{kg}$ ) were intraperitoneally injected. The diabetic training groups received 10 weeks of HIIT or END training following the induction of diabetes. Twenty-four hours following the last training session, blood serum samples were collected for evaluating the concentration of irisin, betatrophin, and insulin hormones through enzymelinked immunosorbent assay. Results: FBG and lipid profiles were measured by biochemical kits. A significant increase in the serum concentration of irisin $(p<0.05)$, betatrophin $(p<0.05)$, and insulin $(p<0.001)$ and significant decrease in the FBG $(P<0.01)$ and lipid profiles $(p<0.01)$ were observed in the Dibt-HIIT group compared to the Dibt-END group. In addition, irisin revealed a significant positive association with betatrophin and insulin values in diabetic training groups $(p<0.01)$. Conclusions: It seems that HIIT leads to a more extensive improvement in diabetic conditions compared to the END training. Therefore, HIIT appears to be an important time-efficient approach for the treatment of type 2 diabetes.
\end{abstract}

Keywords: diabetes mellitus, exercise, endurance training, insulin, streptozotocin

\section{Introduction}

Type 2 diabetes is a highly prevalent disease that accounts for $90 \%-95 \%$ of all cases of diabetes and results from the body's ineffective use of insulin (4). The disease primarily affects adults; however, its incidence in the pediatric population has been growing (27). Obesity and physical inactivity are the major risk factors of this disease. One of the most important treatments for type 2 diabetes is physical activity that helps to maintain balance between energy intake and consumption due to the release of hormones from muscles and adipose tissues (22).

Irisin is a myokine hormone (112 amino acids) that was discovered in 2012 (43). This hormone is produced by the proteolytic breakdown of the fibronectin type III domain

Corresponding author: Mehdi Sadegh, PhD

Department of Physiology, Faculty of Medicine, Arak University of Medical Sciences, Arak 3848176941, Iran Phone: +98 863417 3502(351); Fax: +98 863417 3521; E-mail: m.sadegh@arakmu.ac.ir 
containing protein 5 (FNDC5) (23). Studies have shown that this hormone can help regulate energy metabolism by linking skeletal muscles and other body tissues, including adipose tissues (11). Irisin concentration has been found to be positively correlated with body mass index (25). It has also been reported that irisin concentration is found to be lower in patients with type 2 diabetes, suggesting that irisin may play an important role in glucose tolerance and diabetes (41).

Betatrophin/angiopoietin-like protein 8 contains 198 amino acids and is mainly produced by the liver and adipose tissues (8). By regulating lipoprotein lipase (LPL) activity, it is involved in the lipid metabolism $(7,37)$. Another function of this hormone is to increase the growth and differentiation of pancreatic $\beta$-cells (14). Some studies had shown that, unlike irisin, betatrophin increases in patients with obesity and type 2 diabetes (2). However, Gómez-Ambrosi et al. (13) indicated that serum betatrophin concentrations decreased in patients with obesity and type 2 diabetes.

Some studies have shown that different types of exercise training such as resistance and endurance can affect irisin concentration in various ways (34). On the other hand, it has been reported that betatrophin concentration is reduced after a combination of intensity aerobic and resistance exercise training in obese subjects (1). However, it is unclear whether high-intensity interval training (HIIT) with a lower training-derived energy expenditure and less time spent can have the same effects as moderate-intensity endurance training (END) in improving irisin and betatrophin concentrations, which result in blood glucose control. The answer to this question is important, because lack of time is an obstacle for individuals participating in regular exercise training sessions [38].

Therefore, this study aimed to explore the effects of HIIT and END training on the concentration of circulating irisin, betatrophin, and insulin hormones in diabetic rats.

\section{Materials and Methods}

\section{Animals}

Male Wistar rats (weight: 200-250 g) were kept in cages under controlled humidity $(60 \%)$ and temperature $\left(25 \pm 2{ }^{\circ} \mathrm{C}\right)$ with a 12-h light-dark cycle. The rats had free access to food and water ad libitum. The research and laboratory animal care processes were conducted according to the Guide for the Care and Use of Laboratory Animals (8th edition; National Academies Press; 2011) and approved by the Review Board and Ethics Committee of Arak University of Medical Sciences, Arak, Iran (protocol no.: IR.ARAKMU. rec.1395.353).

\section{Induction and selection of diabetic rats}

For inducing diabetes, after a week of acclimatization and $12 \mathrm{~h}$ of fasting, the rats received a single injection of streptozotocin (STZ; $65 \mathrm{mg} / \mathrm{kg}$, i.p.; Sigma Aldrich, USA) dissolved in citrate buffer $(0.1 \mathrm{M}, \mathrm{pH} 4.5)$ followed $15 \mathrm{~min}$ later by the i.p. administration of $120 \mathrm{mg} / \mathrm{kg}$ of nicotinamide (NA; Sigma Aldrich, USA) dissolved in normal saline. In addition, non-diabetic rats received vehicle citrate buffer. Next, $72 \mathrm{~h}$ following injection, fasting blood glucose (FBG) concentration was measured using a glucometer (Bionime GM300, Germany). Only rats that responded to the single injection with FBG concentrations of more than $250 \mathrm{mg} / \mathrm{dl}$ were considered diabetic and were used in the experiments. 
Animal study design

Twenty-four male Wistar rats were randomly divided into four groups of six as follows: (1) non-diabetic control rats (Cnt) without training, (2) diabetic rats (Dibt) without training, (3) diabetic rats treated with high-intensive interval training (Dibt-HIIT), and (4) diabetic rats receiving END (Dibt-END).

\section{Training protocol}

The END and HIIT protocols were conducted on a 5-channel treadmill for the easier control of speed and time. The diabetic rats were trained 6 days a week for 10 weeks based on the protocol (3) displayed in Table I. Body weight was measured before (day 0) and after (day 70) the training protocols (Table II).

\section{Sampling and analysis of irisin, betatrophin, insulin, FBG, and lipid profiles}

The animals were anesthetized with ketamine $(75 \mathrm{mg} / \mathrm{kg})$ and xylazine $(10 \mathrm{mg} / \mathrm{kg}) 24 \mathrm{~h}$ after the last training session. Blood samples were collected by cardiac puncture and the sera were quickly separated. The serum samples were aliquoted and stored at $-80{ }^{\circ} \mathrm{C}$.

The serum concentrations of irisin, betatrophin, and insulin in the study groups were assessed by the enzyme-linked immunosorbent assay (ELISA) method (ELISA plate reader ELx800TM, BioTek, Winooski, VT, USA) in accordance with the manufacturer's instructions (irisin and betatrophin: Bioassay Technology Laboratory Kits, Shanghai, China; insulin: Monobind Inc., USA). Serum concentrations of FBG, triglyceride (TG), total cholesterol (TC), and high-density lipoprotein (HDL) were measured enzymatically using commercial kits (Pars Azemoon, Tehran, Iran) following the manufacturer's instructions using a spectrophotometer (JENWAY 6505, Europe Union). The serum concentrations of low-density lipoprotein (LDL) and very low-density lipoprotein (VLDL) were calculated by the Friedewald formula (10) as follows: $\mathrm{LDL}=\mathrm{TC}-[\mathrm{HDL}+(\mathrm{TG} / 5)]$ and VLDL $=\mathrm{TG} / 5$. It is noteworthy that the initial and final body weights and FBG of the rats were determined after 10 weeks in fasting condition. Homeostatic model assessment of insulin resistance (HOMAIR) was calculated according to the formula: fasting insulin $($ microU $/ \mathrm{ml}) \times$ fasting glucose $(\mathrm{nmol} / \mathrm{L}) / 22.5$.

\section{Statistical analyses}

The data were expressed as mean \pm SEM of two replicates for the six rats in each group. Oneway analysis of variance and Bonferroni post-hoc test were used to compare the data. Correlations between irisin, betatrophin, and insulin concentration in the Dibt-END and DibtHIIT groups were determined using the Pearson's correlation analysis. The values of $p$ less than 0.05 were considered statistically significant. Statistical analyses were performed using GraphPad Prism software (San Diego, CA, USA).

\section{Results}

Evaluating the FBG and body weight of the experimental groups

The body weights of Cnt and Dibt rats (Table II) increased at day 70 but no statistical significance was found $(p>0.05)$. The introduction of exercise (Dibt-END and Dibt-HIIT) did not modify body weight at day 70 ( $p>0.05$ vs. day 0 ), but diabetic exercised rats have a significantly lower body weight at day 70 as compared to the diabetic non-exercise group 
Table I. Endurance training (END) and high-intensive interval training (HIIT) protocols (19)

\begin{tabular}{|c|c|c|c|c|}
\hline \multirow[b]{2}{*}{ Week } & \multirow[b]{2}{*}{ Day } & \multirow[b]{2}{*}{ END } & \multicolumn{2}{|c|}{ HIIT } \\
\hline & & & Odd day & Even day \\
\hline \multirow[t]{6}{*}{ Week 1} & 1 & $20 \mathrm{~min}, 27 \mathrm{~m} / \mathrm{min}$ & 2 intervals, $40 \mathrm{~m} / \mathrm{min}, 3 \mathrm{~min}$ & \\
\hline & 2 & $22 \mathrm{~min}, 27 \mathrm{~m} / \mathrm{min}$ & & 3 intervals, $54 \mathrm{~m} / \mathrm{min}, 30 \mathrm{~s}$ \\
\hline & 3 & $24 \mathrm{~min}, 27 \mathrm{~m} / \mathrm{min}$ & 2 intervals, $40 \mathrm{~m} / \mathrm{min}, 3 \mathrm{~min}$ & \\
\hline & 4 & $24 \mathrm{~min}, 27 \mathrm{~m} / \mathrm{min}$ & & 5 intervals, $54 \mathrm{~m} / \mathrm{min}, 30 \mathrm{~s}$ \\
\hline & 5 & $28 \mathrm{~min}, 27 \mathrm{~m} / \mathrm{min}$ & 2 intervals, $40 \mathrm{~m} / \mathrm{min}, 3 \mathrm{~min}$ & \\
\hline & 6 & $30 \mathrm{~min}, 27 \mathrm{~m} / \mathrm{min}$ & & 7 intervals, $54 \mathrm{~m} / \mathrm{min}, 30 \mathrm{~s}$ \\
\hline \multirow[t]{6}{*}{ Week 2} & 1 & $32 \mathrm{~min}, 27 \mathrm{~m} / \mathrm{min}$ & 3 intervals, $40 \mathrm{~m} / \mathrm{min}, 3 \mathrm{~min}$ & \\
\hline & 2 & $34 \mathrm{~min}, 27 \mathrm{~m} / \mathrm{min}$ & & 9 intervals, $54 \mathrm{~m} / \mathrm{min}, 30 \mathrm{~s}$ \\
\hline & 3 & $36 \mathrm{~min}, 27 \mathrm{~m} / \mathrm{min}$ & 3 intervals, $40 \mathrm{~m} / \mathrm{min}, 3 \mathrm{~min}$ & \\
\hline & 4 & $38 \mathrm{~min}, 27 \mathrm{~m} / \mathrm{min}$ & & 11 intervals, $54 \mathrm{~m} / \mathrm{min}, 30 \mathrm{~s}$ \\
\hline & 5 & $40 \mathrm{~min}, 27 \mathrm{~m} / \mathrm{min}$ & 3 intervals, $40 \mathrm{~m} / \mathrm{min}, 3 \mathrm{~min}$ & \\
\hline & 6 & $42 \mathrm{~min}, 27 \mathrm{~m} / \mathrm{min}$ & & 13 intervals, $54 \mathrm{~m} / \mathrm{min}, 30 \mathrm{~s}$ \\
\hline \multirow[t]{6}{*}{ Week 3} & 1 & $44 \mathrm{~min}, 27 \mathrm{~m} / \mathrm{min}$ & 2 intervals, $40 \mathrm{~m} / \mathrm{min}, 3 \mathrm{~min}$ & \\
\hline & 2 & $46 \mathrm{~min}, 27 \mathrm{~m} / \mathrm{min}$ & & 15 intervals, $54 \mathrm{~m} / \mathrm{min}, 30 \mathrm{~s}$ \\
\hline & 3 & $48 \mathrm{~min}, 27 \mathrm{~m} / \mathrm{min}$ & 4 intervals, $40 \mathrm{~m} / \mathrm{min}, 3 \mathrm{~min}$ & \\
\hline & 4 & $50 \mathrm{~min}, 27 \mathrm{~m} / \mathrm{min}$ & & 17 intervals, $54 \mathrm{~m} / \mathrm{min}, 30 \mathrm{~s}$ \\
\hline & 5 & $52 \mathrm{~min}, 27 \mathrm{~m} / \mathrm{min}$ & 4 intervals, $40 \mathrm{~m} / \mathrm{min}, 3 \mathrm{~min}$ & \\
\hline & 6 & $54 \mathrm{~min}, 27 \mathrm{~m} / \mathrm{min}$ & & 19 intervals, $54 \mathrm{~m} / \mathrm{min}, 30 \mathrm{~s}$ \\
\hline \multirow[t]{6}{*}{ Week 4} & 1 & $56 \mathrm{~min}, 27 \mathrm{~m} / \mathrm{min}$ & 5 intervals, $40 \mathrm{~m} / \mathrm{min}, 3 \mathrm{~min}$ & \\
\hline & 2 & $58 \mathrm{~min}, 27 \mathrm{~m} / \mathrm{min}$ & & 19 intervals, $54 \mathrm{~m} / \mathrm{min}, 30 \mathrm{~s}$ \\
\hline & 3 & $60 \mathrm{~min}, 27 \mathrm{~m} / \mathrm{min}$ & 5 intervals, $40 \mathrm{~m} / \mathrm{min}, 3 \mathrm{~min}$ & \\
\hline & 4 & $60 \mathrm{~min}, 27 \mathrm{~m} / \mathrm{min}$ & & 20 intervals, $54 \mathrm{~m} / \mathrm{min}, 30 \mathrm{~s}$ \\
\hline & 5 & $60 \mathrm{~min}, 27 \mathrm{~m} / \mathrm{min}$ & 6 intervals, $40 \mathrm{~m} / \mathrm{min}, 3 \mathrm{~min}$ & \\
\hline & 6 & $60 \mathrm{~min}, 27 \mathrm{~m} / \mathrm{min}$ & & 20 intervals, $54 \mathrm{~m} / \mathrm{min}, 30 \mathrm{~s}$ \\
\hline $\begin{array}{r}\text { Weeks } \\
5-10 \\
\end{array}$ & Jan 6 & $\begin{array}{c}60 \mathrm{~min}, 27 \mathrm{~m} / \mathrm{min} \text { to the end } \\
\text { of } 10 \text { th week }\end{array}$ & $\begin{array}{c}6 \text { intervals, } 40 \mathrm{~m} / \mathrm{min}, 3 \mathrm{~min} \\
\text { to the end of } 10 \text { th week }\end{array}$ & $\begin{array}{c}20 \text { intervals, } 54 \mathrm{~m} / \mathrm{min}, 30 \mathrm{~s} \\
\text { to the end of } 10 \text { th week }\end{array}$ \\
\hline
\end{tabular}

( $p<0.05$ vs. Dibt). FBG in the Cnt group was not different on day 70 ( $p>0.05$ vs. day 0$)$. On days 0 and 70, FBG in the diabetic groups was nearly three times higher as compared to $\mathrm{Cnt}$ group $(p<0.05)$. The END group showed a twofold reduction in FBG when compared with Dibt ( $p<0.05$ vs. Dibt). In the high-intensity interval group, FBG was threefold lower when compared with sedentary diabetic animals $(p<0.05$ vs. Dibt). Although both training 
Table II. Effect of END and HIIT training protocols on fasting blood glucose (FBG) concentration and body weight

\begin{tabular}{|l|c|c|c|c|c|c|}
\hline \multirow{2}{*}{ Group } & \multicolumn{3}{|c|}{ FBG (mmol/L) } & \multicolumn{3}{c|}{ Body weight (g) } \\
\cline { 2 - 7 } & Day 0 & Day 70 & $\begin{array}{c}\Delta \text { FBG } \\
(\mathbf{m m o l} / \mathbf{L})\end{array}$ & Day 0 & Day 70 & $\begin{array}{c}\Delta \text { Body } \\
\text { weight }\end{array}$ \\
\hline Cnt & $4.82 \pm 0.7$ & $3.91 \pm 0.2$ & $-0.91 \pm 6.7$ & $219.4 \pm 71$ & $250.4 \pm 38$ & $31 \pm 18$ \\
\hline Dibt & $14.94 \pm 0.2^{\mathrm{a}}$ & $17.81 \pm 0.2^{\mathrm{a}}$ & $2.87 \pm 8.9$ & $223.6 \pm 36$ & $270.6 \pm 48$ & $47 \pm 23$ \\
\hline Dibt-END & $17.37 \pm 0.1^{\mathrm{a}}$ & $9.62 \pm 0.5^{\mathrm{a}, \mathrm{b}}$ & $-7.75 \pm 4.6$ & $224.3 \pm 20$ & $227.4 \pm 38^{\mathrm{a}}$ & $31 \pm 41$ \\
\hline Dibt-HIIT & $18.33 \pm 0.9^{\mathrm{a}}$ & $5.84 \pm 0.4^{\mathrm{a}, \mathrm{b}, \mathrm{c}}$ & $-12.49 \pm 3.5$ & $219.2 \pm 80$ & $224.7 \pm 37^{\mathrm{a}}$ & $5.2 \pm 31$ \\
\hline
\end{tabular}

Data are expressed as mean $\pm \mathrm{SEM}$; for all groups $n=6$. END: endurance training; HIIT: high-intensity interval training.

${ }^{\mathrm{a}} p<0.05$ in comparison with Cnt (days 0 and 70 ).

${ }^{\mathrm{b}} p<0.05$ in comparison with Dibt (day 70).

${ }^{\mathrm{c}} p<0.05$ in comparison with Dibt-END (day 70)

protocols resulted in significantly reduced FBG values, HIIT training was significantly more effective than END $(p<0.05)$.

Significant increase in irisin due to training protocols in diabetic rats

These results were obtained at the end of the 10-week training in all groups (Fig. 1). The difference in serum irisin concentration between Cnt rats $(16.96 \pm 0.64, n=6)$ and Dibt rats $(14.60 \pm 0.64, n=6)$ was not significant. Serum irisin concentration in Dibt-END rats was $33.60 \pm 1.68, n=6$, which was significantly higher as compared to Dibt rats $(14.60 \pm 0.64$, $n=6 ; p<0.001)$. In addition, serum irisin concentration in Dibt-HIIT rats was $39.77 \pm 0.92$, $n=6$, which was significantly higher as compared to Dibt rats $(14.60 \pm 0.64, n=6$; $p<0.001)$. Notably, the serum irisin concentration was significantly higher in the DibtHIIT rats as compared to the Dibt-END rats $(p<0.01)$.

Significant increase in betatrophin due to training protocols in diabetic rats

These results were also evaluated at the end of the 10-week training in all groups (Fig. 2). There was a significant difference between the serum betatrophin concentration of Cnt rats

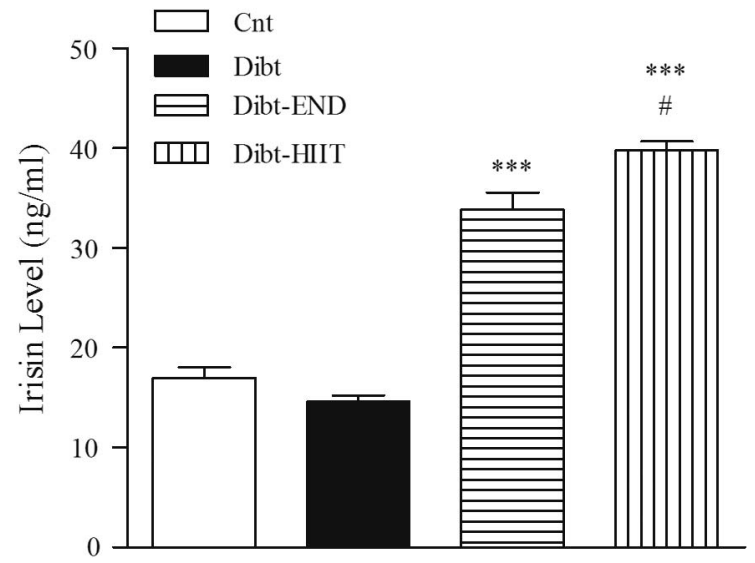

Fig. 1. Concentration of irisin in the experimental groups. Data are mean $\pm \mathrm{SEM} ; n=6$ for all groups; $* * * p<0.001$ compared with Dibt; ${ }^{\#} p<0.05$ compared with Dibt-END 


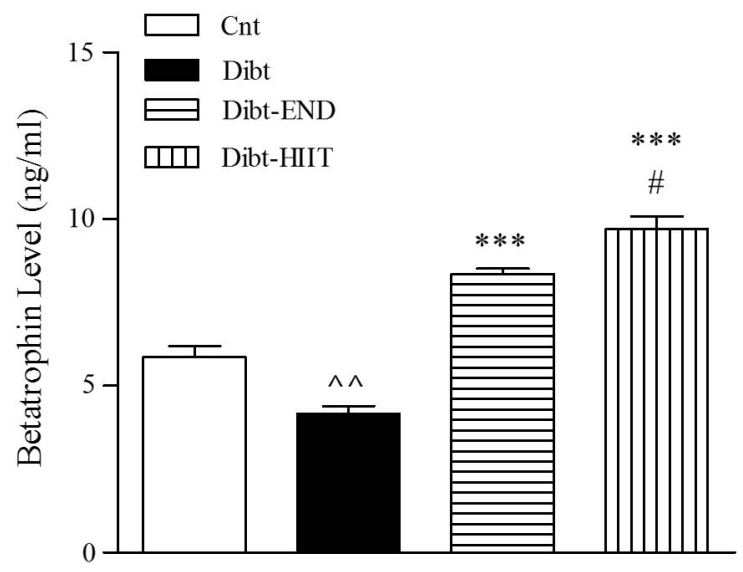

Fig. 2. Concentration of betatrophin in the experimental groups. Data are mean \pm SEM; $n=6$ for all groups; ${ }^{\wedge} p<0.01$ compared with Cnt; $* * * p<0.001$ compared with Dibt; ${ }^{\#} p<0.05$ compared with Dibt-END

$(5.85 \pm 0.33, n=6)$ and that of Dibt $(4 \pm 0.17, n=6 ; p<0.05)$. The serum concentration of betatrophin in the Dibt-END group was $(8.35 \pm 0.16, n=6)$ and was significantly higher as compared to Dibt rats $(4 \pm 0.17, n=6 ; p<0.001)$. Serum concentration of betatrophin in the Dibt-HIIT rats was $(9.69 \pm 0.38, n=6)$ and was significantly higher as compared to Dibt rats $(4 \pm 0.17, n=6 ; p<0.001)$. It is worth noting that the serum betatrophin concentration was significantly higher in Dibt-HIIT rats as compared to the Dibt-END rats $(p<0.05)$.

\section{HIIT protocol seems more effective in increasing serum insulin concentration and reducing} HOMA-IR

Figure 3 shows the changes of insulin levels in normal and diabetic rats after training with END and HIIT for 70 days. Insulin serum concentration in the Dibt rats $(2.48 \pm 0.37, n=6)$ was significantly lower as compared to Cnt rats $(4.16 \pm 0.54, n=6 ; p<0.05)$. Insulin serum concentration increased significantly in the Dibt-END $(4.18 \pm 0.17, n=6 ; p<0.05)$ and in the Dibt-HIIT $(6.91 \pm 0.30, n=6 ; p<0.001)$ rats as compared with Dibt rats. In addition, the high-intensity protocol induced a higher insulin serum concentration than endurance exercise
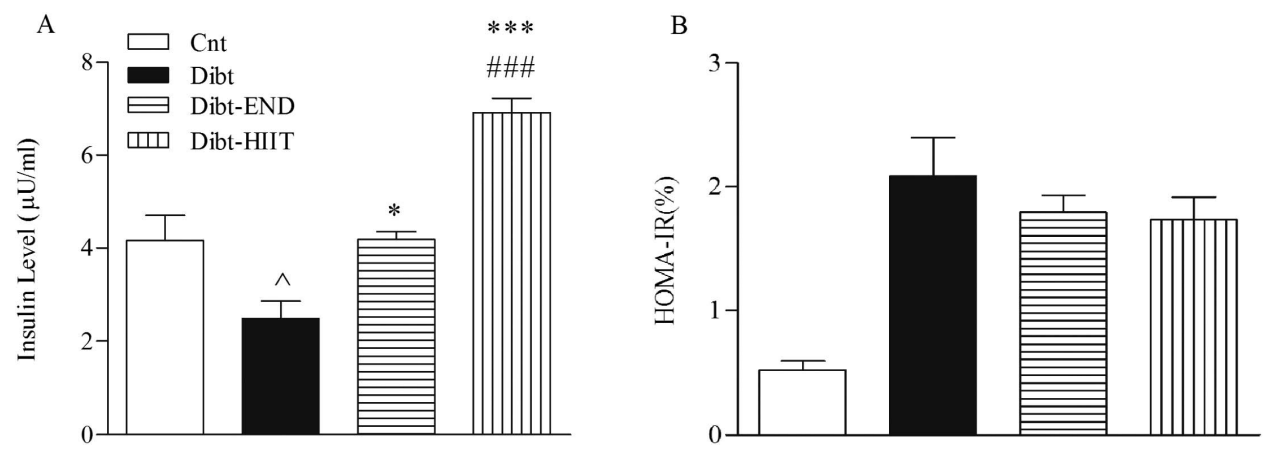

Fig. 3. Insulin serum concentration and HOMA-IR in the experimental groups. Serum concentration of insulin was significantly increased following the training protocols. Additionally, HIIT training was significantly more effective in improving insulin level than END. HOMA-IR decreased following the training protocols. HIIT was more effective in improving insulin resistance than END. Data are mean $\pm \mathrm{SEM} ; n=6$ for all groups; ${ }^{\wedge} p<0.05$ compared with Cnt; ${ }^{*} p<0.05$ compared with Dibt; ${ }^{* * *} p<0.001$ compared with Dibt; ${ }^{\# \#} p<0.05$ compared with Dibt-END 
$(p<0.05$ HIIT vs. END). This result suggests that HIIT training was more effective to increase insulin concentration than END. On the other hand, HOMA-IR assessment revealed an increase in insulin resistance in Dibt rats, which decreased after END and HIIT training, although no statistical difference was observed. Furthermore, there was no significant difference between END and HIIT training in insulin resistance.

Assessment of correlation between irisin and betatrophin as well insulin in Dibt-END and Dibt-HIIT groups

As shown in Fig. 4A, the irisin level was positively and significantly associated with values of betatrophin $(r=0.787, p<0.05)$ and insulin $(r=0.721, p<0.05)$ in Dibt rats that were submitted to END. In addition, as demonstrated in Fig. 4B, in Dibt rats submitted to HIIT training, the positive correlation of irisin increased slightly and maintained significance with betatrophin $(r=0.871, p<0.001)$ and insulin $(r=0.731, p<0.05)$ concentrations.

HIIT training protocol seems more effective on lipid profile of plasma

The effect of HIIT and END training on lipid profile is shown in Table III. The TG, TC, VLDL, and LDL concentrations in the serum were significantly higher in Dibt than in Cnt rats $(p<0.001)$. HIIT and END training significantly decreased the serum TG, TC, VLDL, and
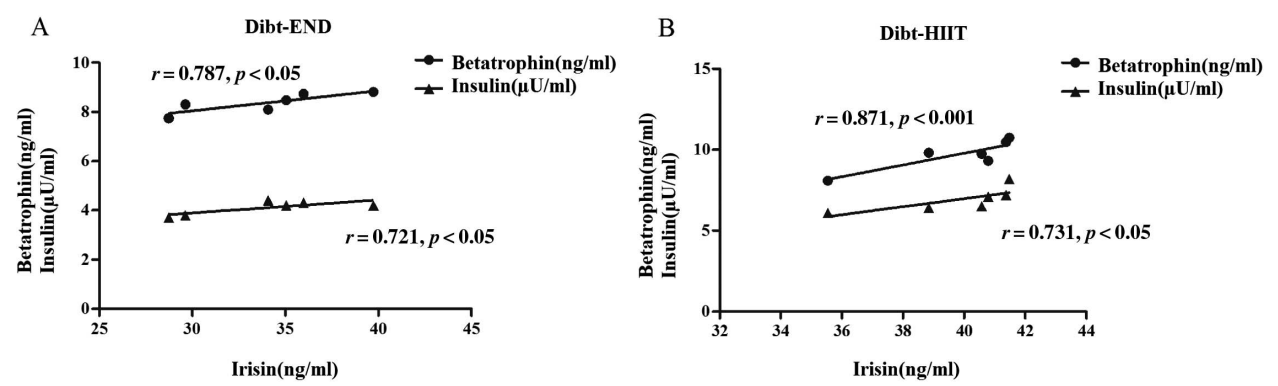

Fig. 4. Correlations between irisin concentration and betatrophin/insulin in Dibt-END and Dibt-HIIT groups. Pearson's analysis for correlation verified that serum irisin concentration was positively and significantly associated with betatrophin and insulin in Dibt-END (A) and Dibt-HIIT (B) groups

Table III. Effect of END and HIIT training protocols on lipids profile

\begin{tabular}{|l|c|c|c|c|c|}
\hline Groups & $\begin{array}{c}\text { Triglyceride } \\
(\mathbf{m g} / \mathbf{d l})\end{array}$ & $\begin{array}{c}\text { Total cholesterol } \\
(\mathbf{m g} / \mathbf{d l})\end{array}$ & LDL (mg/dl) & VLDL (mg/dl) & HDL (mg/dl) \\
\hline Cnt & $5.2 \pm 68$ & $53.6 \pm 2.4$ & $28.6 \pm 0.9$ & $13.3 \pm 0.9$ & $31.5 \pm 1.9$ \\
\hline Dibt & $130.5 \pm 17.4^{\mathrm{a}}$ & $70.6 \pm 3.4^{\mathrm{a}}$ & $37.8 \pm 1.9^{\mathrm{a}}$ & $24.3 \pm 1.2^{\mathrm{a}}$ & $24.1 \pm 1.1^{\mathrm{a}}$ \\
\hline Dibt-END & $60.5 \pm 7.3^{\mathrm{a}, \mathrm{b}}$ & $56 \pm 3^{\mathrm{b}}$ & $25.5 \pm 0.9^{\mathrm{b}}$ & $15.6 \pm 3.2^{\mathrm{b}}$ & $30.8 \pm 1.7^{\mathrm{b}}$ \\
\hline Dibt-HIIT & $51.6 \pm 5.5^{\mathrm{a}, \mathrm{b}, \mathrm{c}}$ & $50.1 \pm 4.6^{\mathrm{b}}$ & $31.5 \pm 2.8$ & $14 \pm 1.6^{\mathrm{b}}$ & $33.6 \pm 1.6^{\mathrm{b}}$ \\
\hline
\end{tabular}

Data are expressed as mean \pm SEM; for each group $n=6$. LDL: low-density lipoprotein; HDL: high-density lipoprotein; VLDL: very low-density lipoprotein; END: endurance training; HIIT: high-intensity interval training. ${ }^{\mathrm{a}} p<0.05$ in comparison with Cnt.

${ }^{\mathrm{b}} p<0.05$ in comparison with Dibt.

${ }^{\mathrm{c}} p<0.05$ in comparison with Dibt-END 
LDL concentrations as compared to Dibt rats $(p<0.001)$. HDL serum concentration increased significantly in the Dibt-END and Dibt-HIIT diabetic rats as compared with Dibt rats $(p<0.001)$. In addition, there was no significant difference between the effects of training protocols (HIIT and END) on serum TG, TC, VLDL, and LDL ( $p>0.05$ vs. Cnt).

\section{Discussion}

The results of this study showed significant beneficial effects of these two types of exercise protocols on serum concentrations of irisin, betatrophin, insulin, FBG, and lipid profiles in Dibt rats, although HIIT had a stronger effect as compared to END. Thus, 10 weeks of HIIT significantly increased the concentrations of irisin, betatrophin, and insulin, whereas it significantly decreased FBG and lipid profiles as compared to END. This study showed a significant positive correlation between irisin, betatrophin, and insulin concentrations in the training groups.

In a previous study, three methods of exercise were investigated in men with metabolic syndrome that included both resistance and endurance at high and low intensities. The serum concentration of irisin was observed to be increased after all exercises protocols (18). In this regard, Huh et al. (17) reported a significant increase in the irisin concentration in response to HIIT relative to medium-intensity continuous exercise activity, indicating that the intensity of physical activity is an effective factor in stimulating irisin release. Contrary to these results, it has been reported that irisin concentration in the serum of rats receiving regular aerobic exercise was not significantly different as compared to the control group (35). The discrepancy between these results can be associated with differences in exercise protocols, particularly exercise intensity, as well as the subjects.

Our findings indicated that 10 weeks of HIIT and END training increased the serum concentrations of irisin and insulin and reduced FBG and insulin resistance indices in Dibt rats. Consistent with our results, Zhang et al. (44) found that irisin stimulates transformation of white to brown adipose tissue by provoking MAPK p38 and ERK pathways and has anti-obesity and anti-diabetic effects. Skeletal muscles are the main tissues for the utilization of blood glucose but glucose uptake is reduced in type 2 diabetes partly due to the lack of glucose-4 transporter (GLUT4) $(28,32)$. On the other hand, Xin et al. (40) showed that injection of irisin in type 2 diabetes increased GLUT4 in skeletal muscle and decreased enzymes involved in the gluconeogenesis. Therefore, elevated irisin is associated with glucose utilization by increasing glucose uptake and inhibiting gluconeogenesis (12), which may explain our result for FBG improvement while irisin increased.

Although various mechanisms have been proposed regarding the impact of exercise training on glucose and insulin resistance, there is limited information on the role of exerciseinduced irisin changes in glucose and insulin resistance. In accordance with our results, Cauza et al. (5) demonstrated that strength training compared to END has a more pronounced effect to reduce insulin resistance in patients with type 2 diabetes mellitus. Exercise improves insulin sensitivity by enhancing the effects of insulin receptor substrates (IRS-1 and IRS-2) and activating phosphatidylinositol-3 kinase (6). Promoting the sensitivity of IRS creates a separate cascade of phosphorylation reactions, which leads to a wide range of metabolic and mitogenic effects of insulin (16). For example, the activation of phosphatidylinositol-3 kinase results in the transfer of GLUT4 to the cell surface (20). 
In this study, the serum level of betatrophin significantly decreased in the diabetic control group; following two training protocols, the serum concentration of betatrophin increased, although this increase was greater in the HIIT group than in the END group. It has been shown that in obese rats with diet-induced type 2 diabetes, the serum level of betatrophin increased, whereas in a rat model of type 1 diabetes induced by STZ injection, the serum level of betatrophin was reduced (19). This finding reflects the positive correlation of body weight with the serum level of insulin and the lack of correlation of body weight with blood glucose (19). These results were in line with the findings of this study, where diabetes was induced by a single dose of STZ and NA.

In accordance with our results, irisin was shown to increase the expression of betatrophin. Physical activity was shown to increase muscle PGC1- $\alpha$ expression, which consequently boosted the expression of FNDC5 and irisin concentration. The rise in irisin increased the expression of UCP1 in white fat cells and activated MAPK p38, which ultimately led to an increase in the expression of betatrophin (26). Moreover, the increase in betatrophin leads to regeneration of beta-pancreatic cells and improved insulin resistance (44). Contrary to our findings, there was a decrease in the serum concentration of betatrophin in obese individuals who participated in a combined exercise program (aerobic and resistance) for 3 months. A possible reason for this observation could be the simultaneous reduction of insulin serum level and insulin resistance (1). There are few studies evaluating the effect of different types of physical exercise on betatrophin; therefore, no further comparisons were possible.

Type 2 diabetes, in addition to causing hyperglycemia and hyperinsulinism, usually disrupts the production and metabolism of serum lipoproteins, a disorder known as diabetic dyslipidemia, usually associated with increased TG, LDL-C, and HDL-C associated with cholesterol (33). The results of this study showed that continued END and HIIT significantly decreased TG, LDL, VLDL, and TC and significantly increased HDL; however, HIIT was more effective than END in lipid profile modulation. In accordance with this study, data reported by Heo and Kim (15) showed that END promoted a reduction of plasma TC and TG along with an increase in HDL-C concentration in Dibt rats. Furthermore, Mahmoudi et al. (21) reported that HIIT significantly reduces the TC and TG and increases the HDL-C.

One of the mechanisms by which exercise can affect the lipid profile is the increased activity of LPL due to physical activity (31). LPL hydrolyzes circulating TG-rich lipoprotein, such as those found in chylomicrons and VLDL, into two free fatty acids (FFA) and one monoacylglycerol molecule. It is also involved in promoting the cellular uptake of chylomicron remnants, cholesterol-rich lipoproteins, and FFAs $(24,30)$. On the other hand, studies have shown that betatrophin is associated with metabolism and lipoprotein homeostasis in mammalian cells: for instance, Zhang et al.'s study (45) showed that an increase in betatrophin significantly reduced FFA, in agreement with our findings. Moreover, TG in the liver and adipose tissue cultures was suppressed by the expression of the adipose TG lipase gene.

Our correlation analysis showed that in the training groups, there is a positive and significant correlation between irisin, insulin, and betatrophin. In line with our results, Wang et al. (36) reported that there is a positive correlation between irisin and betatrophin in patients with type 2 diabetes. On the other hand, Xie et al. (39) showed a positive correlation between irisin and betatrophin only in patients with normal blood glucose. In individuals with type 2 diabetes, the correlation was negative, which is different from our results. Exercise stimulates muscle expression of PGC1- $\alpha$ that induces the expression of FNDC5 and the secretion of 
irisin. The increase in irisin secretion induces UCP1expression in white adipose tissue, which is mediated by p38 MAPK activation (9) that can also promote the expression of betatrophin (29). Betatrophin can stimulate the secretion of insulin from pancreatic beta cells (42). Together, this series of events can define a possible mechanism for the positive and significant correlation we observed between irisin, betatrophin, and insulin in this study.

Based on the results presented here, HIIT training had a stronger effect to improve lipid and glycemic profile in Dibt rats than END training. Since HIIT induces a higher physiological stress than END, the stress can be related to the physiological improvements, although more studies and evidence are necessary to address this point.

\section{Conclusions}

HIIT leads to greater improvements in FBG, lipid profiles and irisin, betatrophin, insulin concentrations as compared to END. HIIT, therefore, appears to be an important timeefficient treatment for type 2 diabetes. In addition, this study showed a significant positive correlation between irisin, betatrophin, and insulin concentrations in the training groups, which may indicate a significant role for irisin and betatrophin in alleviating the diabetic condition.

\section{Acknowledgements}

This research was supported by Arak University of Medical Sciences, Arak, Iran.

\section{Conflict of interest}

The authors declare no conflict of interest.

\section{REFERENCES}

1. Abu-Farha M, Sriraman D, Cherian P, AlKhairi I, Elkum N, Behbehani K, Abubaker J: Circulating ANGPTL8/ betatrophin is increased in obesity and reduced after exercise training. PLoS One 11, e0147367 (2016)

2. Adamska A, Lebkowska A, Jacewicz M, Krentowska A, Hryniewicka J, Wolczynski S, Gorska M, Kowalska I: Serum concentrations of betatrophin and its association with indirect indices of insulin resistance and beta cell function in women with polycystic ovary syndrome. Int. J. Endocrinol. 2316986, 18 (2017)

3. Afzalpour ME, Chadorneshin HT, Foadoddini M, Eivari HA: Comparing interval and continuous exercise training regimens on neurotrophic factors in rat brain. Physiol. Behav. 147, 78-83 (2015)

4. American Diabetes Association: Diagnosis and classification of diabetes mellitus. Diabetes Care. 32, S62-S67 (2009)

5. Cauza E, Hanusch-Enserer U, Strasser B, Ludvik B, Metz-Schimmerl S, Pacini G, Wagner O, Georg P, Prager R, Kostner K, Dunky A, Haber P: The relative benefits of endurance and strength training on the metabolic factors and muscle function of people with type 2 diabetes mellitus. Arch. Phys. Med. Rehabil. 86, 1527-1533 (2005)

6. Chibalin AV, Yu M, Ryder JW, Song XM, Galuska D, Krook A, Wallberg-Henriksson H, Zierath JR: Exerciseinduced changes in expression and activity of proteins involved in insulin signal transduction in skeletal muscle: differential effects on insulin-receptor substrates 1 and 2. Proc. Natl. Acad. Sci. U. S. A. 97, 38-43 (2000)

7. Chung HS, Lee MJ, Hwang SY, Lee HJ, Yoo HJ, Seo J-A, Kim SG, Kim NH, Baik SH, Choi DS, Kim SM, Choi KM: Circulating angiopoietin-like protein 8 (ANGPTL8) and ANGPTL3 concentrations in relation to anthropometric and metabolic profiles in Korean children: a prospective cohort study. Cardiovasc. Diabetol. 15,1 (2016)

8. Cox AR, Lam CJ, Bonnyman CW, Chavez J, Rios JS, Kushner JA: Angiopoietin-like protein 8 (ANGPTL8)/ betatrophin overexpression does not increase beta cell proliferation in mice. Diabetologia 58, 1523-1531 (2015) 
9. Dinas PC, Lahart IM, Timmons JA, Svensson P-A, Koutedakis Y, Flouris AD, Metsios GS: Effects of physical activity on the link between PGC-1a and FNDC5 in muscle, circulating irisin and UCP1 of white adipocytes in humans: a systematic review. F1000Res. 6, 286 (2017)

10. Friedewald WT, Levy RI, Fredrickson DS: Estimation of the concentration of low-density lipoprotein cholesterol in plasma, without use of the preparative ultracentrifuge. Clin. Chem. 18, 499-502 (1972)

11. Gamas L, Matafome P, Seiça R: Irisin and myonectin regulation in the insulin resistant muscle: implications to adipose tissue: muscle crosstalk. J. Diabetes Res. 2015, 359159 (2015)

12. Gizaw M, Anandakumar P, Debela T: A review on the role of irisin in insulin resistance and type 2 diabetes mellitus. J. Pharmacopuncture 20, 235-242 (2017)

13. Gómez-Ambrosi J, Pascual E, Catalán V, Rodríguez A, Ramírez B, Silva C, Gil MJ, Salvador J, Frühbeck G: Circulating betatrophin concentrations are decreased in human obesity and type 2 diabetes. J. Clin. Endocrinol. Metab. 99, E2004-E2009 (2014)

14. Gusarova V, Alexa CA, Na E, Stevis PE, Xin Y, Bonner-Weir S, Cohen JC, Hobbs HH, Murphy AJ, Yancopoulos GD, Gromada J: ANGPTL8 (betatrophin) does not control pancreatic beta cell expansion. Cell 159, 691-696 (2014)

15. Heo M, Kim E: Effects of endurance training on lipid metabolism and glycosylated hemoglobin levels in streptozotocin-induced type 2 diabetic rats on a high-fat diet. J. Phys. Ther. Sci. 25, 989-992 (2013)

16. Howlett KF, Sakamoto K, Yu H, Goodyear LJ, Hargreaves M: Insulin-stimulated insulin receptor substrate-2associated phosphatidylinositol 3-kinase activity is enhanced in human skeletal muscle after exercise. Metabolism 55, 1046-1052 (2006)

17. Huh JY, Mougios V, Kabasakalis A, Fatouros I, Siopi A, Douroudos II, Filippaios A, Panagiotou G, Park KH, Mantzoros CS: Exercise-induced irisin secretion is independent of age or fitness level and increased irisin may directly modulate muscle metabolism through AMPK activation. J. Clin. Endocrinol. Metab. 99, E2154-E6211 (2014)

18. Huh JY, Siopi A, Mougios V, Park KH, Mantzoros CS: Irisin in response to exercise in humans with and without metabolic syndrome. J. Clin. Endocrinol. Metab. 100, E453-E457 (2015)

19. Li E, Nakata M, Shinozaki A, Yang Y, Zhang B, Yada T: Betatrophin expression is promoted in obese hyperinsulinemic type 2 but not type 1 diabetic mice. Endocr. J. 63, 611-619 (2016)

20. Liu T, Yu B, Kakino M, Fujimoto H, Ando Y, Hakuno F, Takahashi SI: A novel IRS-1-associated protein, DGKzeta regulates GLUT4 translocation in 3T3-L1 adipocytes. Sci. Rep. 6, 35438 (2016)

21. Mahmoudi Y, Gholami M, Nikbakht H, Ebrahim K, Bakhtiyari S: Effect of high intensity interval training with metformin on lipid profiles and HbA1c in diabetic rats. Iranian J. Diabetes Obes. 10, 144-150 (2018)

22. Makhdoumi P, Zarif-Yeganeh M, Hedayati M: Physical activity and obesity related hormones. Zahedan J. Res. Med. Sci. 16, 6-11 (2014)

23. Matsuo Y, Gleitsmann K, Mangner N, Werner S, Fischer T, Bowen TS, Kricke A, Matsumoto Y, Kurabayashi M, Schuler G, Linke A, Adams V: Fibronectin type III domain containing 5 expression in skeletal muscle in chronic heart failure-relevance of inflammatory cytokines. J. Cachexia Sarcopenia Muscle 6, 62-72 (2015)

24. Mead JR, Irvine SA, Ramji DP: Lipoprotein lipase: structure, function, regulation, and role in disease. J. Mol. Med. (Berl.) 80, 753-769 (2002)

25. Mehrabian S, Taheri E, Karkhaneh M, Qorbani M, Hosseini S: Association of circulating irisin levels with normal weight obesity, glycemic and lipid profile. J. Diabetes Metab. Disord. 15, 17 (2015)

26. Norheim F, Langleite TM, Hjorth M, Holen T, Kielland A, Stadheim HK, Gulseth HL, Birkeland KI, Jensen J, Drevon CA: The effects of acute and chronic exercise on PGC- $1 \alpha$, irisin and browning of subcutaneous adipose tissue in humans. FEBS J. 281, 739-749 (2014)

27. Reinehr T: Type 2 diabetes mellitus in children and adolescents. World J. Diabetes 4, 270-281 (2013)

28. Richter EA, Hargreaves M: Exercise, GLUT4, and skeletal muscle glucose uptake. Physiol. Rev. 93, 993-1017 (2013)

29. Sanchis-Gomar F, Perez-Quilis C: The p38-PGC-1 $\alpha$-irisin-betatrophin axis: exploring new pathways in insulin resistance. Adipocyte 3, 67-68 (2014)

30. Sasaki T, Nakata R, Inoue H, Shimizu M, Inoue J, Sato R: Role of AMPK and PPARgamma1 in exercise-induced lipoprotein lipase in skeletal muscle. Am. J. Physiol. Endocrinol. Metab. 306, E1085-E1092 (2014)

31. Stubbe I, Hansson P, Gustafson A, Nilsson-Ehle P: Plasma lipoproteins and lipolytic enzyme activities during endurance training in sedentary men: changes in high-density lipoprotein subfractions and composition. Metabolism 32, 1120-1128 (1983) 
32. Sylow L, Nielsen IL, Kleinert M, Moller LL, Ploug T, Schjerling P, Bilan PJ, Klip A, Jensen TE, Richter EA: Rac1 governs exercise-stimulated glucose uptake in skeletal muscle through regulation of GLUT4 translocation in mice. J. Physiol. 594, 4997-5008 (2016)

33. Tangvarasittichai S: Oxidative stress, insulin resistance, dyslipidemia and type 2 diabetes mellitus. World J. Diabetes 6, 456 (2015)

34. Tsuchiya Y, Ando D, Takamatsu K, Goto K: Resistance exercise induces a greater irisin response than endurance exercise. Metabolism 64, 1042-1050 (2015)

35. Uysal N, Yuksel O, Kizildag S, Yuce Z, Gumus H, Karakilic A, Guvendi G, Koc B, Kandis S, Ates M: Regular aerobic exercise correlates with reduced anxiety and increased levels of irisin in brain and white adipose tissue. Neurosci. Lett. 676, 92-97 (2018)

36. Wang L, Song J, Wang C, Lin P, Liang K, Sun Y, He T, Li W, Zhao R, Qin J, Lu Y, Liu J, Liu F, Hou X, Chen L: Circulating levels of betatrophin and irisin are not associated with pancreatic $\beta$-cell function in previously diagnosed type 2 diabetes mellitus patients. J. Diabetes Res. 2016, 2616539 (2016)

37. Wang Y, Quagliarini F, Gusarova V, Gromada J, Valenzuela DM, Cohen JC, Hobbs HH: Mice lacking ANGPTL8 (betatrophin) manifest disrupted triglyceride metabolism without impaired glucose homeostasis. Proc. Natl. Acad. Sci. U. S. A. 110, 16109-16114 (2013)

38. Winding KM, Munch GW, Iepsen UW, Van Hall G, Pedersen BK, Mortensen SP: The effect on glycaemic control of low-volume high-intensity interval training versus endurance training in individuals with type 2 diabetes. Diabetes Obes. Metab. 20, 1131-1139 (2018)

39. Xie X, Gao T, Yang M, Chen P, Jin H, Yang L, Yu X: Associations of betatrophin levels with irisin in Chinese women with normal glucose tolerance. Diabetol. Metab. Syndr. 7, 26 (2015)

40. Xin C, Liu J, Zhang J, Zhu D, Wang H, Xiong L, Lee Y, Ye J, Lian K, Xu C, Zhang L, Wang Q, Liu Y, Tao L: Irisin improves fatty acid oxidation and glucose utilization in type 2 diabetes by regulating the AMPK signaling pathway. Int. J. Obes. (Lond.) 40, 443-451 (2016)

41. Yan B, Shi X, Zhang H, Pan L, Ma Z, Liu S, Liu Y, Li X, Yang S, Li Z: Association of serum irisin with metabolic syndrome in obese Chinese adults. PLoS One 9, e94235 (2014)

42. Yi P, Park J-S, Melton DA: Betatrophin: a hormone that controls pancreatic $\beta$ cell proliferation. Cell 153, 747-758 (2013)

43. Zhang W, Chang L, Zhang C, Zhang R, Li Z, Chai B, Li J, Chen E, Mulholland M: Irisin: a myokine with locomotor activity. Neurosci. Lett. 595, 7-11 (2015)

44. Zhang Y, Li R, Meng Y, Li S, Donelan W, Zhao Y, Qi L, Zhang M, Wang X, Cui T, Yang LJ, Tang D: Irisin stimulates browning of white adipocytes through mitogen-activated protein kinase p38 MAP kinase and ERK MAP kinase signaling. Diabetes 63, 514-25 (2014)

45. Zhang Y, Li S, Donelan W, Xie C, Wang H, Wu Q, Purich DL, Reeves WH, Tang D, Yang L-J: Angiopoietinlike protein 8 (betatrophin) is a stress-response protein that down-regulates expression of adipocyte triglyceride lipase. Biochim. Biophys. Acta. 1861, 130-137 (2016) 